\title{
GDAŃSK UNIVERSITY DEVELOPMENT FOUNDATION
}

Gdańsk University Development Foundation was established on 10th February 1991. One of the founders is Lech Waressa, President of Poland; and on the board are distinguished scholars, artists, economists and politicians, one of whom is the former Prime Minister Jan Krzysztof Bielecki. The urgent need to support the activities of Gdańsk University inspired the establishment of the Foundation. We hope thereby to restore the role of learning in the social, economic and cultural life of the Gdańsk Region and country.

Gdańsk University is one of the youngest in the country. Although it has faced many hardships since its establishment 20 years ago, it has become one of the important, dynamic academic centers in Poland. New fields of studies added to those already existing. Research programmes were expanded to keep up with achievements in Poland and the world. The University employs a highly qualified staff, most of whom are actively involved in the changes taking place in the country.

\section{Foundation Objectives}

The prime role of the Foundation is the development of the University of Gdańsk.

Its statutory aims are :

- development of the University material base, the building of the University campus and the Central Library which also embraces the Central Marine Library,

- financial support of research projects in all fields represented at the University,

- staff training to introduce the latest achievements in the fields of science, new technologies, culture and the arts,

- organizing scientific and cultural exchange between members of the staff and students of our University and those of academic centers abroad,

- promoting the University and its achievements at home and abroad.

\section{Legal Status of the Foundation}

The Foundation is a private institution with its own legal status. It may conduct research and business activities, be a partner or member of similar organizations or associations and participate in various business undertakings, both in Poland and abroad. It may enter into any form of cooperation and be entitled to assistance from the government. 
The Operation of the Foundation :

- establishing, contacts and initiating cooperation in biology, economics, languages, physics, geography, history, mathematics, law, psychology, sociology, as well as ecology, oceanography and political studies. This includes resolving interdisciplinary problems which cannot otherwise be dealt with on a faculty level,

- canvassing for and distributing of financial and material assistance for research projects undertaken by various units or individuals,

- finding researchers to work on projects suggested by sponsors,

- finding sponsors to support programmes carried out by the University staff,

- inviting expert and independent assessments of the above projects to ensure their high scientific standard. The results are made available to sponsors,

- discretion in respect of projects, reviews of theses, dissertations and papers and in relations between partners,

- organizing post - graduate studies for overseas students,

- organizing conferences, seminars, and traineeships for Polish and foreign specialists also issuing and distributing promotional materials.

All profits from donations, subventions and the Foundation's own work are used for its statutory activities.

\section{Board of the Foundation:}

Andrzej Friedrich Phd (Chairman), Józef Przybylski PhD, DSc., Anna Żuchowska Msc, Eng., Jarosław Białkowski MSc.

Address :

ul. Bażyńskiego 1A, 80-952 Gdańsk, Poland, Tel. / Fax : (PL-58)-52-34-32, Tlx : 051-20-24 REKUG

Foundation's Account :

Wielkopolski Bank Kredytowy S.A., o / Gdańsk 351809-512398-132-3 